\title{
新技术和新方法推动生态系统生态学研究
}

\author{
温学发
}

中国科学院地理科学与资源研究所生态系统网络观测与模拟重点实验室, 北京 100101; 中国科学院大学资源与环境学院, 北京 100190

温学发 (2020). 新技术和新方法推动生态系统生态学研究. 植物生态学报, 44, 287-290. DOI: 10.17521/cjpe.2020.0081

\section{Advances in new technologies and methods to promote ecosystem ecology research}

\section{WEN Xue-Fa*}

Key Laboratory of Ecosystem Network Observation and Modeling, Institute of Geographic Sciences and Natural Resources Research, Chinese Academy of Sciences, Beijing 100101, China; and College of Resources and Environment, University of Chinese Academy of Sciences, Beijing 100190, China

Wen XF (2020). Advances in new technologies and methods to promote ecosystem ecology research. Chinese Journal of Plant Ecology, 44, 287-290. DOI: 10.17521/cjpe.2020.0081

随着 “五位一体”“生态文明建设”发展总布局, “绿水青山”“金山银山”等一系列理论和理念相继提 出, 国家、社会和公众把生态学提高到了前所未有 的高度。生态系统是地球表层的重要组成部分, 又 是人类生存和发展的物质基础(方精云等, 2018)。生 态系统 (ecosystem) 概念由英国生态学家 Tansley (1935)正式提出, 其与2001年正式提出的地球关键 带(critical zone)概念的差异主要体现在垂直尺度上 (Richter \& Billing, 2015)。生态系统生态学(ecosystem ecology)是2011年成为一级学科的生态学下面7 个二级学科方向之一。生态系统生态学是以生态系 统为研究对象的生态系统科学, 研究生态系统的组 成与结构、过程与功能、发展与演替, 系统内和系 统间的信息传递、能量流动和物质循环以及自然变 化和人为活动的影响与调控机制的学科(蔡晓明, 2000; 于贵瑞等, 2020)。有效应对全球变化和维持 地球系统的可持续发展需要观测、模拟和评估地球 系统变化与生态系统服务功能。

生态系统研究被认为是当代生态学发展的标志, 具有独特的研究对象、理论体系和研究方法。生态 系统生态学是在生物群落学基础上结合现代科学技 术的应用和学科间的相互渗透而发展起来的(于贵 瑞等, 2016, 2020)。生态系统研究技术和方法的研发 与创新是推进生态系统研究的重要途径, 也是实现 原创性研究的重要基础。例如, Wehr等(2016)结合浴
度相关和稳定同位素技术首次证明白天生态系统呼 吸低于夜间, 这表明在生态系统尺度上存在光抑制 叶片呼吸的效应; Hicks Pries等(2017)基于全土壤剖 面增温技术证明不同深度的土壤呼吸对增温的响应 没有显著差别, 与传统表层土壤增温相比, 全土壤 剖面增温处理会引起更多的土壤碳排放。同时,

《Nature Methods》《Methods in Ecology and Evolution》等专业性技术和方法类期刊出版发行, 也从侧 面证明新技术和新方法是推动生态学及生态系统生 态学等学科研究乃至科学进步的重要驱动力。

生态系统研究的对象包括生物部分一生产者 (植物)、消费者(动物和人类)和分解者(微生物), 以 及非生物部分也称环境系统一包括生物活动的空 间和参与生物生理代谢过程的各种要素(土壤、大气 等), 是生态系统的物质和能量的来源(Chapin III et al., 2011; Begon et al., 2016)。生态系统研究需要 从三维空间和时间尺度上考虑生态系统结构和功能 的变化。研究尺度不仅要考虑样点尺度、景观尺度 和区域尺度等, 还需要考虑土壤-根系-微生物、土壤植物-大气、生态系统内(生物-环境)、生态系统间(环 境梯度)等(van Nuland et al., 2016)。生态系统受气 候、植被、土壤、动物和人类活动等综合影响, 客 观需要构建天地空一体化的观测、实验、模拟与评 价的生态系统研究技术和方法体系。从生态系统野 外考察与调查、采样与分析、移动与定位观测、控

收稿日期Received: 2020-03-26 接受日期Accepted: 2020-03-29

基金项目: 国家重点研发计划(2017YFC0503904)和国家自然科学基金(41830860)。Supported by the National Key R\&D Program of China (2017YFC0503904), and the National Natural Science Foundation of China (41830860).

* E-mail: wenxf@igsnrr.ac.cn 
制与模拟实验、遥感观测、模型模拟, 到基于生态 大数据的系统评价等, 新技术和方法的进步可以促 进生态系统生态学相关研究。

在中国科学院学部和国家自然科学基金委员会 联合资助的, 由方精云院士主持的“生态系统生态 学学科发展战略项目”的支持下, 我们组织了本期 “生态学研究的技术与方法”专辑。相关技术和方法 在中国科学院学部第83次科学与技术前沿论坛“生 态系统生态学”论坛进行了汇报和讨论。从生态系统 生态学研究技术和方法的角度, 本专辑收录了13篇 综述文章, 内容涉及生态系统通量观测如浴度相关 技术(陈世苹等, 2020), 通量梯度技术(赵佳玉等, 2020)和箱式通量技术(魏杰等, 2020); 生态系统控 制实验如增温(朱彪和陈迎, 2020)和大型完全开放 式 $\mathrm{CO}_{2} / \mathrm{O}_{3}$ 气体浓度增加控制(FACE) 实验(冯兆忠等, 2020); 生态系统水(汤显辉等, 2020), 碳(葛体达等, 2020), 氮(方运霆等, 2020)同位素自然和人工示踪; 生物标志物(冯晓娟等, 2020), 微生物组学(高贵锋 和禇海燕, 2020), 野外动物监测(肖文宏等, 2020), 生态遥感(郭庆华等, 2020)以及生物圈模型(彭书时 等, 2020), 等技术和方法的应用及其进展。

生态系统碳氮水等物质交换主要发生在植被大气和土壤-大气界面, 主要是通过生物(植物叶片、 根系、土壤微生物、动物等)生理活动和代谢活动将 生态系统复杂的碳-氮-水等耦合循环过程联结起 来。目前, 浴度相关法(陈世苹等, 2020), 箱式通量 法(魏杰等, 2020)和通量梯度法(赵佳玉等, 2020)是 植被-大气和土壤-大气界面温室气体及其同位素通 量的主要观测技术和方法, 有助于揭示温室气体在 土壤-植物-大气连续体的产生、迁移和转化的相关 过程与机制等。

生态系统对全球变化要素如 $\mathrm{CO}_{2}$ 浓度、温度、 氮沉降、水分和耕作措施等的综合响应特征与机制 非常重要。陆地生态系统碳循环对气温、 $\mathrm{CO}_{2} / \mathrm{O}_{3}$ 浓 度升高等的反馈是决定未来气候变化强度的重要因 素。生态系统尺度的野外增温控制实验(朱彪和陈迎, 2020)和FACE实验(冯兆忠等, 2020)等是在野外条件 下陆地生态系统对全球变化因素响应与适应的主要 研究手段。

同位素技术具有指示、示踪和整合功能。随着 氢和氧等水同位素技术的发展与应用, 通过测量和 分析土壤、植物茎叶或大气中所含水分的氧氢同位
素可以揭示生态系统水循环的过程与机制、树木年 轮或叶蜡烷烃中记录的气候或生理生态过程信息 (汤显辉等, 2020)。随着碳同位素示踪技术的广泛应 用和迅速发展, 多种碳同位素示踪技术及其与其他 光谱和微生物探针技术联用, 对于揭示从微观到宏 观尺度的碳循环过程起着重要促进作用(葛体达等, 2020)。氮稳定同位素技术的进步使得氮循环的研究 从海洋和陆地生态系统扩展到大气和冰芯样品的研 究中; 例如对生态系统氮状态的指示指标从利用土 壤和植物叶片氮稳定同位素比值 $\left(\delta^{15} \mathrm{~N}\right)$ 发展到无机 氮 $\delta^{15} \mathrm{~N}$ (方运霆等, 2020)。

定量表征土壤组成及结构及其与功能的关系对 生态系统生态学研究具有重要意义。记载了原始生 物母质(如高等植物、微生物等)分子结构信息的生 物标志物在天然有机质(包括土壤、沉积物、气溶胶 等)的来源解析、历史植被和古气候重建、有机碳的 周转与转化评估、食物网分析等方面都有重要的应 用, 已成为生态系统研究中新兴的示踪和指示方法 (冯晓娟等, 2020)。

微生物数量庞大、种类繁多, 是生物地球化学 循环过程的驱动者, 微生物组学研究的发展强烈依 赖于微生物组学的技术和方法(高贵锋和褚海燕, 2020)。高通量测序和质谱等技术的突破, 使得我们 可以从DNA、RNA、蛋白质和代谢物等不同水平解 析微生物组, 以获得更为全面的微生物组学信息。 现代生态学经过20世纪的发展已经累积了大量成熟 的理论和模型, 但这些理论和模型大都建立在宏观 生态学的基础上, 是否也适用于微生物领域, 仍需要 更多的微生物组学数据支撑。在技术应用上多组学技 术结合的研究策略更有利于全面解析微生物组。

动物是生态系统研究和保护管理的重要生物类 群, 其中脊椎动物、土壤动物、昆虫及小型节肢动 物是目前动物种群监测以及生物多样性监测的重要 指示类群(肖文宏等, 2020)。红外相机抓拍技术和 GPS跟踪技术在脊椎动物监测中提供的物种信息和 位置与运动数据准确、标准、高效, 减少了对动物 及其栖息地的影响。随着分子生物学技术的发展, 分子技术如高通量测序也逐渐应用在土壤动物和昆 虫等无脊椎动物的监测研究中。节肢动物多样性监 测的新方法和新设施的开发研究在多样性监测工作 中将被重视和鼓励, 对无脊椎动物多样性的保护有 着重要意义。 
目前, 生态学本身正在向着更大尺度发展, 如 景观生态学、全球生态学、宏观生态学等, 现有研究 手段亟需融入新的技术手段(郭庆华等, 2020)。不同 地物因其物理性质和化学组成差异, 所反射、吸收和 发射的电磁波信息不同, 遥感技术通过分析电磁波 信息从而识别地物属性和特征, 反演生态系统的组 成以及能量流动和物质循环过程中的关键要素。随 着遥感传感器和运载平台迅速迭代更新, 遥感技术 能够通过机器人、汽车、无人机、飞机和卫星等平 台, 搭载微波雷达、激光雷达、多/高光谱等各种传 感器, 实现对生态系统中生物和环境因子的高频次、 长时序、多尺度的立体观测, 为生态系统生态学开展 物质循环和能量流动等研究提供翔实的观测资料。

随着全球变化科学的不断发展, 预测未来陆地 生物圈的变化和其对地球气候的反馈逐渐成为全球 变化科学核心科学问题之一。陆地生物圈模型不仅 是生态系统生态学研究的重要工具, 也是地球系统 模式中的重要模块(彭书时等, 2020)。陆地生物圈模 型在评估过去陆地生物圈的变化及其归因和预测未 来陆地生物圈对气候变化的响应中发挥重要作用, 也成为研究区域和全球尺度陆地生态系统和环境变 化问题的重要方法。未来气候变化预测的不确定性 有一半来自于陆地生物圈, 例如陆地生物圈碳循环 对气候变化的响应与反馈。发展陆地生物圈模型和 降低陆地生物圈模型的不确定性也被认为是准确预 测未来地球气候变化的关键。

尽管本专辑的出版有望促进学术界对生态系统 生态学研究技术和方法的重视和认识, 但因篇幅有 限只能涉及部分主要的技术和方法, 期望起到抛砖 引玉的作用和效果, 以期促进生态系统研究的新技 术和新方法的研发与应用。科学始于观测, 没有观 测, 准确的科学是不可能的。近年来, 随着科学技术 的发展, 以及网络化的生态观测、联网控制实验和 定量遥感技术的迅速发展, 推动了多尺度生态系统 观测与实验研究(于贵瑞等, 2016, 2020)。目前, 生态 学理论与方法(代码C0309)包括“理论生态学、生态 观测技术与方法以及生态模拟和评价” 成为国家自 然科学基金委员会生命学部生态学的重要资助研究 方向。新的仪器、技术和方法的研发和创新将成为 解决生态系统生态学研究热点与难点问题的重要工 具与途径。

致谢 此专辑由方精云院士主持的中国科学院学部
和国家自然科学基金委员会联合资助的“生态系统 生态学学科发展战略项目”资助。感谢主编方精云院 士在此次专辑组织过程中给予的指导与支持。

\section{参考文献}

Begon M, Townsend CR, Harper JL (2016). Ecology: from Individual to Ecosystem. 4th ed. Li B, Zhang DY, Wang DH, translation. Higher Education Press, Beijing. [Begon M, Townsend CR, Harper JL (2016). 生态学—从个体 到生态系统. 4版. 李博, 张大勇, 王德华, 译. 高等教 育出版社. 北京.]

Cai XM (2000). Ecosystem Ecology. Science Press, Beijing. [蔡 晓明 (2000). 生态系统生态学. 科学出版社, 北京.]

Chapin III FS, Masten PA, Vitousek PM (2011). Principles of Terrestrial Ecosystem Ecology. 2nd ed. Springer, New York.

Chen SP, You CH, Hu ZM, Chen Z, Zhang LM, Wang QF (2020). Eddy covariance technique and its applications in flux observations of terrestrial ecosystems. Chinese Journal of Plant Ecology, 44, 291-304. [陈世苹, 游翠海, 胡 中民, 陈智, 张雷明, 王秋风 (2020). 浴度相关技术及 其在陆地生态系统通量研究中的应用. 植物生态学报, 44, 291-304.]

Fang JY, Zhu JL, Shi Y (2018). The responses of ecosystems to global warming. Chinese Science Bulletin, 63, 136-140. [方精云, 朱江玲, 石岳 (2018). 生态系统对全球变暖 的响应. 科学通报, 63, 136-140.]

Fang YT, Liu DW, Zhu FF, Tu Y, Li SL, Huang SN, Quan Zhi, Wang A (2020). Applications of nitrogen stable isotope techniques in the study of nitrogen cycling in terrestrial ecosystems. Chinese Journal of Plant Ecology, 44, 373383. [方运霆, 刘冬伟, 朱飞飞, 图影, 李善龙, 黄韶楠, 全智, 王盎 (2020). 氮稳定同位素技术在陆地生态系统 氮循环研究中的应用. 植物生态学报, 44, 373-383.]

Feng XJ, Wang YY, Liu T, Jia J, Dai GH, Ma T, Liu ZG (2020). Biomarkers and their applications in ecosystem research. Chinese Journal of Plant Ecology, 44, 384-394. [冯晓娟, 王依云, 刘婷, 贾娟, 戴国华, 马田, 刘宗广 (2020). 生物标志物及其在生态系统研究中的应用. 植 物生态学报, 44, 384-394.]

Feng ZZ, Xu YS, Shang B (2020). Free-Air Concentration Enrichment (FACE) techniques, experimental approach and its application in the field of global change ecology: a review. Chinese Journal of Plant Ecology, 44, 340-349. [冯 兆忠, 徐彦森, 尚博 (2020). FACE实验技术和方法回 顾及其在全球变化研究中的应用. 植物生态学报, 44, 340-349.]

Gao GF, Chu HY (2020). Techniques and methods of microbiomics and their applications. Chinese Journal of Plant Ecology, 44, 395-408. [高贵锋, 褚海燕 (2020). 微生物 组学的技术和方法及其应用. 植物生态学报, 44 , 
395-408.]

Ge TD, Wang DD, Zhu ZK, Wei L, Wei XM, Wu JS (2020). Tracing technology of carbon isotope and its applications to studies of carbon cycling in terrestrial ecosystem. Chinese Journal of Plant Ecology, 44, 360-372. [葛体达, 王 东东, 祝贞科, 魏亮, 魏晓梦, 吴金水 (2020). 碳同位 素示踪技术及其在陆地生态系统碳循环研究中的应用 与展望. 植物生态学报, 44, 360-372.]

Guo QH, Hu TY, Ma Q, Xu KX, Yang QL, Sun QH, Li YM, Su YJ (2020). Advances for the new remote sensing technology in ecosystem ecology research. Chinese Journal of Plant Ecology, 44, 418-435. [郭庆华, 胡天宇, 马勤, 徐 可心, 杨秋丽, 孙千惠, 李玉美, 苏艳军 (2020). 新一 代遥感技术助力生态系统生态学研究. 植物生态学报, 44, 418-435.]

Hicks Pries CE, Castanha C, Porras RC, Torn MS (2017). The whole-soil carbon flux in response to warming. Science, 355, 1420-1423.

Peng SS, Yue C, Chang JF (2020). Developments and applications for terrestrial biosphere model. Chinese Journal of Plant Ecology, 44, 436-448. [彭书时, 岳超, 常锦峰 (2020). 陆地生物圈模型的发展与应用. 植物生态学报, 44, 436-448.]

Richter DD, Billings SA (2015). “One physical system”: Tansley's ecosystem as Earth's critical zone. New Phytologist, 206, 900-912.

Tang XH, Chen YL, Li F, Song X (2020). Water isotope analysis for tracing ecosystem processes: measurement techniques, ecological applications, and future challenges. Chinese Journal of Plant Ecology, 44, 350-359. [汤显辉, 陈永乐, 李芳, 宋欣 (2020). 水同位素分析与生态系统 过程示踪: 技术、应用以及未来挑战. 植物生态学报, 44, 350-359.]

Tansley AG (1935). The use and abuse of vegetational concepts and terms. Ecology, 16, 284-307.

van Nuland ME, Wooliver RC, Pfennigwerth AA, Read QD, Ware IM, Mueller L, Fordyce JA, Schweitzer JA, Bailey JK (2016). Plant-soil feedbacks: connecting ecosystem ecology and evolution. Functional Ecology, 30, 1032-1042.

Wehr R, Munger JW, McManus JB, Nelson DD, Zahniser MS, Davidson EA, Wofsy SC, Saleska SR (2016). Seasonality of temperate forest photosynthesis and daytime respiration.
Nature, 534, 680-683.

Wei J, Chen CH, Wang JY, Wen XF (2020). Theory, hypothesis and application advance in chamber-based technology and methods for flux measurement. Chinese Journal of Plant Ecology, 44, 318-329. [魏杰, 陈昌华, 王晶苑, 温 学发 (2020). 箱式通量观测技术和方法的理论假设及 其应用进展. 植物生态学报, 44, 318-329.]

Xiao WH, Zhou QS, Zhu CD, Wu DH, Xiao ZS (2020). Advances in techniques and methods of wildlife monitoring. Chinese Journal of Plant Ecology, 44, 409-417. [肖文宏, 周青松, 朱朝东, 吴东辉, 肖治术 (2020). 野生动物监 测技术和方法应用进展与展望. 植物生态学报, 44, 409-417.]

Yu GR, Fang HJ, Tian J, He NP, Gao Y, Zhao GL (2016). Chapter 17 Pandect of ecosystem ecology//Yu ZL. Ecology: Current Knowledge and Future Challenges. Higher Education Press, Beijing. [于贵瑞, 方华军, 田静, 何念 鹏, 高扬, 赵桂玲 (2016). 第17章 生态系统生态学总 论//于振良. 生态学的现状与发展趋势. 高等教育出版 社, 北京.]

Yu GR, Niu SL, Fang HJ (2020). Chapter 4 Research progress of ecosystem ecology//Ecological Society of China. Review of the Development of Ecology in China in the Past 40 Years. Science Press, Beijing. [于贵瑞, 牛书丽, 方华 军 (2020). 第4章 生态系统生态学研究进展//中国生态 学学会. 中国生态学学科40年发展回顾. 科学出版社, 北京.]

Zhao JY, Xiao W, Zhang M, Wang JY, Wen XF, Lee XH (2020). Applications and prospect of the flux-gradient method in measuring the greenhouse gases and isotope fluxes. Chinese Journal of Plant Ecology, 44, 305-317. [赵佳玉, 肖薇, 张弥, 王晶苑, 温学发, 李旭辉 (2020). 通量梯度法在温室气体及同位素通量观测研究中的应 用与展望. 植物生态学报, 44, 305-317.]

Zhu B, Chen Y (2020). Techniques and methods for field warming manipulation experiments in terrestrial ecosystems. Chinese Journal of Plant Ecology, 44, 330-339. [朱 彪, 陈迎 (2020). 陆地生态系统野外增温控制实验的技 术与方法. 植物生态学报, 44, 330-339.]

责任编辑：谢 巍 